Article

\title{
Enhanced Removal of Trichloroethylene in Water Using Nano-ZnO/Polybutadiene Rubber Composites
}

\author{
Dae Gyu Jang ${ }^{1}$, Chang Hyuk Ahn ${ }^{2}$, June Seok Choi ${ }^{2}$, Jong Ho Kim ${ }^{3}$, Jong Kyu Kim ${ }^{4, *}$ and \\ Jin Chul Joo ${ }^{5, *}$ \\ 1 Environmental and Plant Engineering Research Institute, University of Science \& Technology, \\ Goyang 10223, Korea; qwkdeorb@hanmail.net \\ 2 Environmental and Plant Engineering Research Institute, Korea Institute of Civil Engineering and Building \\ Technology, Goyang 10223, Korea; chahn@kict.re.kr (C.H.A.); jschoi@kict.re.kr (J.S.C.) \\ 3 Department of Chemical Engineering, Chonnam National University, Gwangju 61186, Korea; \\ jonghkim@jnu.ac.kr \\ 4 Department of Civil Engineering, University of Kyungnam, Changwon 51767, Korea \\ 5 Department of Civil and Environmental Engineering, Hanbat National University, Daejeon 34158, Korea \\ * Correspondence: jongkim@kyungnam.ac.kr (J.K.K.); jincjoo@hanbat.ac.kr (J.C.J.); \\ Tel.: +82-55-249-2745 (J.K.K.); +82-42-821-1264 (J.C.J.)
}

Academic Editor: Keith Hohn

Received: 6 July 2016; Accepted: 21 September 2016; Published: 27 September 2016

\begin{abstract}
An innovative nanoscale $\mathrm{ZnO}$ / polybutadiene rubber composite (ZBRC) was developed as a valid alternative to $\mathrm{TiO}_{2}$ particles or immobilized $\mathrm{TiO}_{2}$ for the mineralization of chlorinated hydrocarbons without difficulties in the recovery of nanoscale photocatalyst particles. A synergistic increase in the removal of 1,1,2-trichloroethylene (TCE) through the coupled reaction processes (i.e., sorption, photolysis, and photocatalysis) was observed because sorption of TCE to the ultraviolet(UV)-transparent polybutadiene rubber occurred, and was coupled with the heterogeneous photocatalytic reactions with nanoscale $\mathrm{ZnO}$ particles on the surface of $\mathrm{ZBRC}$. The removal rate of TCE decreased with an increase in the initial concentration of TCE because of both inhibited generation of electron-hole pairs and deficiency of photons to activate $\mathrm{ZnO}$ particles. Also, the TCE removal rate increased as the loading amount of ZBRC increased. Based on satisfactory linear regressions $\left(R^{2} \geq 0.94\right)$ between the apparent degradation rate constant $\left(K_{\mathrm{app}}\right)$ and the initial concentration vs. the ZBRC loading amount, the $K_{\text {app }}$ values can be estimated, a priori, without performing photocatalytic experiments. The removal efficiencies were more significantly affected by the changes in the initial concentration of TCE and the ZBRC loading amounts than by the changes in light intensity and $\mathrm{pH}$ in aqueous solutions. From the results of response surface analysis, the greater removal efficiencies of TCE were achieved with higher $\mathrm{pH}$ values, greater amounts of ZBRC, and greater intensity of light. Based on these results, newly-developed ZBRC with both high removal efficiency and low cost performs as a valid alternative to $\mathrm{TiO}_{2}$ particles or immobilized $\mathrm{TiO}_{2}$ for the mineralization of chlorinated hydrocarbons in various environmental and industrial matrices.
\end{abstract}

Keywords: coupled reaction processes; nanoscale $\mathrm{ZnO}$ /polybutadiene rubber composites (ZBRC); photolysis; photocatalysis; response surface analysis; sorption; trichloroethylene

\section{Introduction}

In the last three decades, heterogeneous photocatalytic oxidation processes with $\mathrm{TiO}_{2}$-based materials and binary oxides have been investigated for the remediation of water resources contaminated by recalcitrant hydrocarbons [1-11]. These studies have reported that highly reactive transitory species (e.g., superoxide radical $\left(\mathrm{O}_{2} \cdot{ }^{-}\right)$, hydroxyl radicals $(\cdot \mathrm{OH})$, and hydrogen peroxide $\left(\mathrm{H}_{2} \mathrm{O}_{2}\right)$ ) involved in the heterogeneous photocatalytic reactions effectively degrade various ambiguous 
refractory chlorinated hydrocarbons (e.g., 4-chlorophenol, $p$-dichlorobenzene, trichloroethylene (TCE), and tetrachloroethylene), and eventually mineralize those chlorinated compounds into carbon dioxide and water $[1,2,5,6,10]$.

While many $\mathrm{TiO}_{2}$-based photocatalysts have been developed with bare $\mathrm{TiO}_{2}$ or modified $\mathrm{TiO}_{2}$ particles, several limitations have still been reported for bare $\mathrm{TiO}_{2}$ or modified $\mathrm{TiO}_{2}$ particles (e.g., a small fraction of photons adsorbed in the visible region and a high electron-hole recombination rate) $[7,8]$. As such, more recent studies have investigated alternative photocatalysts for use in the remediation of contaminated water resources $[7,8]$. Moreover, suspended and fine photocatalyst particles in a slurry system for water treatment would require several processes (i.e., separation, recycling, and regeneration) in large-scale water treatment processes. Thus, $\mathrm{TiO}_{2}$ photocatalytic membrane reactors have been recently developed by integrating hybrid photocatalysis-membrane processes for the complete recovery of photocatalyst particles [12,13].

To avoid the particle recovery process, photocatalyst particles can also be immobilized and stabilized onto various supports (i.e., silica gel, glass fibers and beads, activated carbons, mesoporous clays, cellulose membranes, polymer films, etc.) $[7,10,14,15]$. However, immobilizing photocatalysts to various supports reduces the amount of active sites, enlarges the mass transfer limitations, and increases the operational difficulty with reduced photon penetration $[7,8]$. Considering these limitations and challenges when developing efficient photocatalyst/support composites, a support should be transparent to UV light and should have a good capacity to sorb target recalcitrant hydrocarbons [15]. Additionally, the physicochemical bonds between certain photocatalysts and supports must be strong without reducing the photoactivity.

Although a valid alternative to the use of bare $\mathrm{TiO}_{2}$ or modified $\mathrm{TiO}_{2}$ particles in environmental applications has not yet been found $[8,16]$, nanoscale $\mathrm{ZnO}$ has been shown to be more efficient than that of bare $\mathrm{TiO}_{2}$ or modified $\mathrm{TiO}_{2}$ particles (e.g., its cost effectiveness, slow recombination rate, and excellent photoactivation under visible light illumination) [5,8-11]. For example, the nanoscale zinc oxide $(\mathrm{ZnO})$ photocatalyst has greater photocatalytic efficiency than that of $\mathrm{TiO}_{2}$ in the visible spectrum [17]. Additionally, $\mathrm{ZnO}$ has a band gap that is $3.0 \mathrm{eV}$ lower than that of the anatase $\mathrm{TiO}_{2}$ and has a strong oxidizing power for the photodegradation of organic compounds in aqueous solutions [3,9-11]. Thus, this study investigated nanoscale $\mathrm{ZnO}$ as a valid alternative to $\mathrm{TiO}_{2}$ because of its good optoelectronic, photocatalytic, and chemical properties. To develop a highly efficient $\mathrm{ZnO} /$ support composite, branched polybutadiene rubber (BR) was used because $\mathrm{BR}$ is transparent to UV light, and has a good capacity to sorb recalcitrant hydrocarbons [18].

Many variables that could enhance the photodegradation efficiency of the newly-developed $\mathrm{ZnO} /$ support composite were investigated because the oxidation rates and photocatalytic efficiency can significantly dependent on many reaction configurations (e.g., the loading amount of $\mathrm{ZnO}$, the wavelength and the intensity of light source, the dissolved oxygen, the $\mathrm{pH}$, and the temperature of the aqueous solution, auxiliary oxidizing agent, and coexisting materials, etc.) [1-17]. Therefore, new removal systems using nanoscale $\mathrm{ZnO} /$ polybutadiene rubber composite (ZBRC) that optimize the coupled reactive interactions among UV light, ZBRC, and recalcitrant hydrocarbons in water were developed to overcome the limitations of $\mathrm{TiO}_{2}$ particles or immobilized $\mathrm{TiO}_{2}$.

The research hypothesis tested in this study was that ZBRC has great potential to remove chlorinated hydrocarbons without difficulties in the recovery of photocatalysts. To evaluate this research hypothesis, the coupled removal of TCE in the aqueous phase was systematically evaluated with ZBRC. The specific objectives of this study were (1) to investigate the coupled removal of TCE using ZBRC; (2) to evaluate the effects of the initial concentration of TCE, the loading amount of ZBRC, the intensity of light, and the initial $\mathrm{pH}$ on the removal of TCE; and (3) to optimize the operation parameters to enhance the coupled reactions using response surface analysis. 


\section{Results and Discussion}

\subsection{Characterization of the Nanoscale ZnO/Polybutadiene Rubber Composite (ZBRC)}

The scanning electron microscope (SEM) images of the developed ZBRC at two different magnifications (i.e., $\times 30$ and $\times 10,000)$ as well as the SEM/energy dispersive X-ray (EDX) analysis results are displayed in Figure 1. Both the SEM images and the SEM/EDX analysis results indicated that nanoscale $\mathrm{ZnO}$ particles were successfully entrapped inside both pores and cracks over the surface of the ZBRC. Various pores, cracks, and channels of different sizes were well developed over the BR surface (see Figure 1b) because the surface of the BR specimens was dissolved and swollen by THF molecules, and then quickly dried at $130{ }^{\circ} \mathrm{C}$. Since the swollen $\mathrm{ZnO}$ particle-entrapped BR specimens were contracted through the rapid evaporation of THF molecules, the $\mathrm{ZnO}$ particles were effectively immobilized on the surface of the ZBRC (see Figure 1c,d). After several uses of the ZBRC as an alternative to $\mathrm{TiO}_{2}$ in the mineralization of chlorinated hydrocarbons, the $\mathrm{ZnO}$ particles were still immobilized in the pores, cracks, and channels on the surface (see Figure S1-S7). These results showed that the newly-developed ZBRC is more practical since the mass production of ZBRC is simple and cost effective. The fabricated ZBRC has excellent mechanical strength for long-term applications without any significant loss of $\mathrm{ZnO}$ particles.

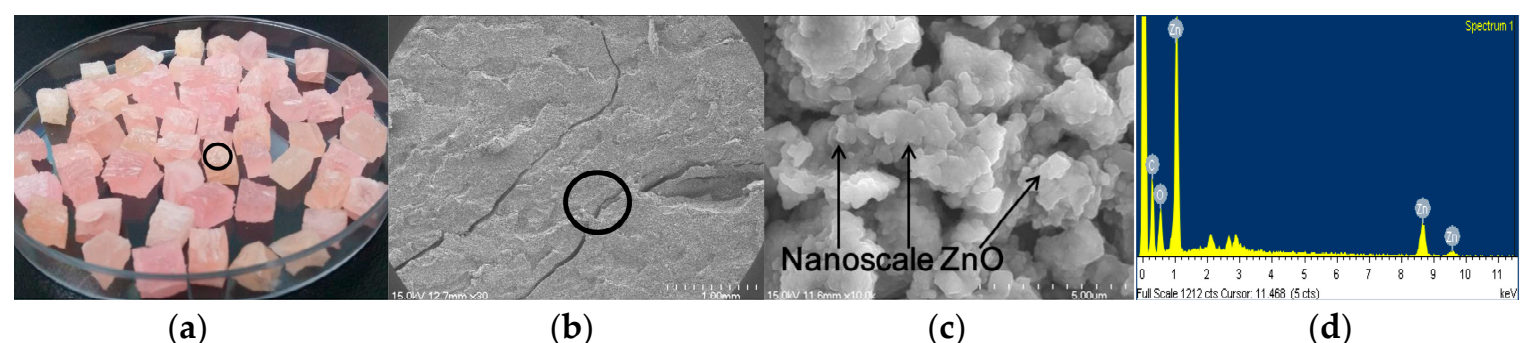

(a)

(b)

(c)

(d)

Figure 1. Scanning electron microscopic (SEM) images of the nanoscale $\mathrm{ZnO} /$ polybutadiene rubber composite (ZBRC): (a) Pictorial view of the developed ZBRC; (b) SEM images of the ZBRC specimen ( $\times 30$ mag.); (c) SEM images of the ZBRC specimen $(\times 10,000$ mag.); (d) Associated energy dispersive X-ray (EDX) analysis of the ZBRC.

\subsection{Coupled Removal of TCE Using the Nanoscale ZnO/Polybutadiene Rubber Composite (ZBRC)}

The TCE removal efficiency in aqueous solutions under various conditions at a $\mathrm{pH}$ of $7.0 \pm 0.2$ is displayed in Figure 2. The concentration changes in the control test were insignificant $\left(C / C_{0}=0.96 \sim 1.03\right)$, and hence, the experimental errors caused by the sorption to the Teflon ${ }^{\circledR}$-lined septa and partitioning to the headspace were not considered in this study.

The TCE removal efficiency in aqueous solutions by sorption to ZBRC was close to $60 \%$, and this higher sorption capacity of ZBRC compared to that of other supports (mesoporous clays and polymer films) [10] was mainly due to the low chain rigidity and the low degree of cross-linking of the amorphous BR structures $[19,20]$. When considering that the dynamic mass transfer of hydrophobic TCE in the aqueous phase to ZBRC involves both partitioning and diffusion of TCE through non-crystalline BR $[19,20]$, the higher TCE sorption capacity to ZBRC with a low degree of cross-linking is expected. Based on these sorption results, the UV-transparent BR support in the ZBRC has an excellent sorption capacity for hydrophobic organic compounds to be degraded.

When comparing the TCE removal efficiencies between photolysis (UV only) and photocatalysis $(\mathrm{UV}+\mathrm{ZBRC})$, the removal efficiencies were significantly improved with the ZBRC under UV irradiation. Because heterogeneous photocatalytic degradation of TCE occurs on the ZBRC surface, highly reactive transitory species effectively degraded ambiguous refractory TCE molecules in the vicinity of the ZBRC surface, indicating that the surface reactions in heterogeneous photocatalysis were more dominant than those of photo-induced photolysis in aqueous solutions. In addition, significant sorption of TCE to the 
UV-transparent amorphous BR support in ZBRC was coupled with the heterogeneous photocatalytic reaction. As shown by the X-ray diffraction (XRD) results (see Figure S8), ZnO immobilized on the surface of $\mathrm{ZBRC}$ retained the inherent properties of $\mathrm{ZnO}$ particles, and the UV-transparent BR support had an excellent sorption capacity for organic compounds.

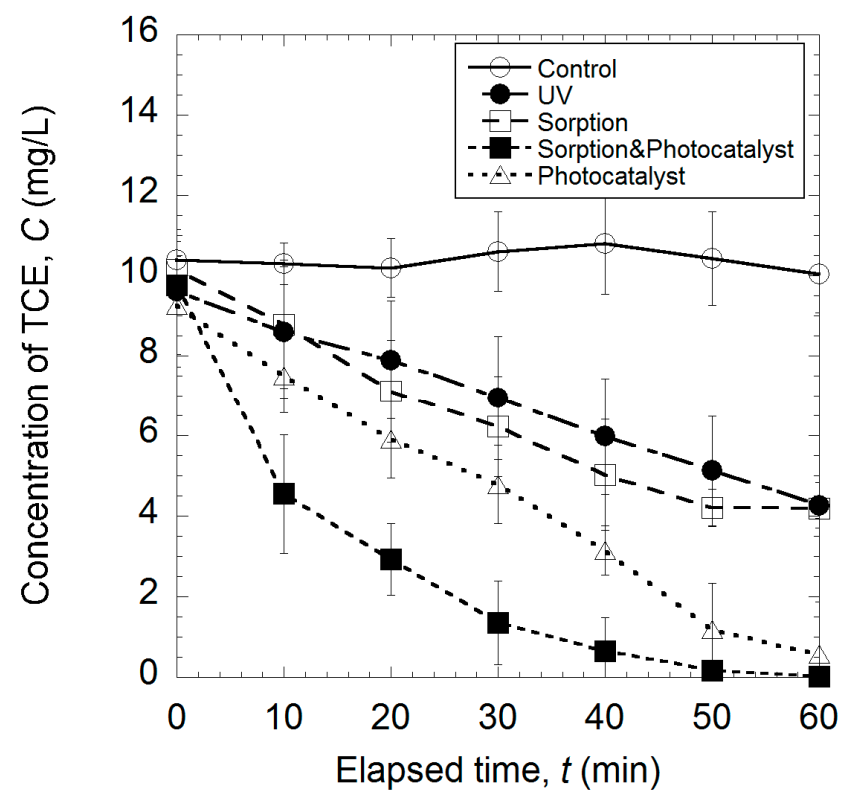

Figure 2. Removal of trichloroethylene (TCE) in aqueous solutions under various conditions at $\mathrm{pH}$ of $7.0 \pm 0.2$ (only TCE solution (control test), TCE solution with $10 \mathrm{~g}$-ZBRC (sorption), TCE solution with UVC intensity of $8.4 \mathrm{~mW} / \mathrm{cm}^{2}$ (photolysis), TCE solution with both $10 \mathrm{~g}$-ZBRC and UVC intensity of $8.4 \mathrm{~mW} / \mathrm{cm}^{2}$ (sorption + photocatalysis), and TCE solution with both 0.05 g-nanoscale $\mathrm{ZnO}$ particles and UVC intensity of $8.4 \mathrm{~mW} / \mathrm{cm}^{2}$ (photocatalysis)).

To determine the degradation pathway of TCE, degradation intermediates were measured using gas chromatography with mass spectrometry. However, no, if any, partial degradation intermediates were observed in this study, suggesting that partial degradation intermediates may not accumulate, and could not be detected by the mass spectral fragmentation analysis used in this study. These results could be due to both the fast and consecutive photocatalytic reactions and the significant sorption capacity of ZBRC for the partial degradation intermediates. These coupled removal reactions can result in less accumulation of partial degradation intermediates in the TCE degradation pathway. However, the comparison of infrared spectra between intact and used ZBRC is required to ensure no accumulation of possibly harmful degradation intermediates.

Based on the chloride mass balance displayed in Table 1, TCE was essentially mineralized after a one-hour batch photocatalytic reaction. As the initial TCE concentrations increased, greater conversion rates of TCE to chloride ion were observed. This result may be attributed to the vigorous sorption of both TCE and degradation intermediates at low TCE concentration. However, at high TCE concentrations, the photocatalytic degradation rate of $\mathrm{ZnO}$ particles is dominant due to the rate-limited mass transfer of TCE to the TCE-sorbed BR support. As also displayed in Figure 3, TCE was mineralized with TOC removal efficiencies of $96.2 \% \pm 2.5 \%$ after a one-hour batch photocatalytic reaction. Consequently, ZBRC was found to be an effective photocatalyst for the removal of TCE in aqueous solutions. 
Table 1. Summary of trichloroethylene conversion rates to chloride under various conditions.

\begin{tabular}{cccccc}
\hline $\begin{array}{c}\text { Initial Conc. } \\
(\mathbf{m g} / \mathbf{L})\end{array}$ & $\begin{array}{c}\text { Loading Amount } \\
(\mathbf{g} / \mathbf{7 6} \mathbf{~ m L})\end{array}$ & $\begin{array}{c}\text { Intensity of } \\
\text { Lamp } \\
\left(\mu \mathbf{W} / \mathbf{c m}^{2}\right)\end{array}$ & $\begin{array}{c}\text { Equivalent } \\
\text { Chloride Conc. } \\
(\mathbf{m g} / \mathbf{L})\end{array}$ & $\begin{array}{c}\text { Measured } \\
\text { Chloride Conc. } \\
(\mathbf{m g} / \mathbf{L})\end{array}$ & $\begin{array}{c}\text { Average } \\
\text { Conversion } \\
\text { Rate }(\%)\end{array}$ \\
\hline 0.5 & 10 & 84 & 0.42 & N.D. & N.A. $^{\text {b }}$ \\
1 & 10 & 84 & 0.83 & $0.53 \pm 0.09$ & 63.6 \\
5 & 10 & 84 & 4.2 & $2.8 \pm 0.85$ & 67.2 \\
10 & 10 & 84 & 8.3 & $6.6 \pm 1.20$ & 79.2 \\
20 & 10 & 84 & 16.7 & $13.9 \pm 2.8$ & 83.4 \\
\hline
\end{tabular}

${ }^{a}$ N.D.: Not Detectable; ${ }^{b}$ N.A.: Not Available.

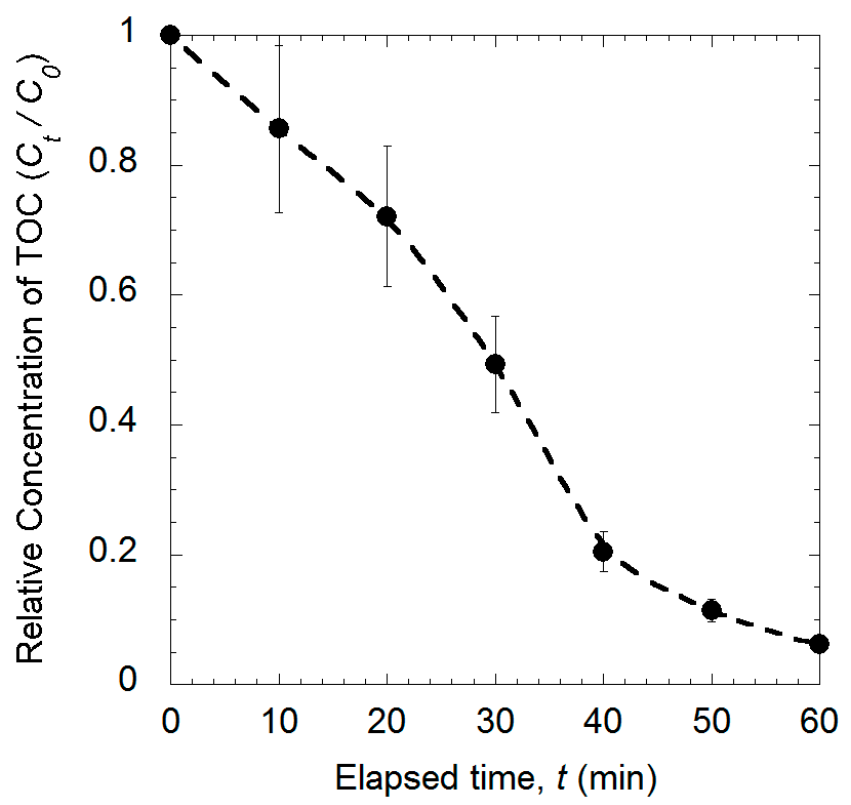

Figure 3. The decrease of total organic carbon (TOC) concentration with the elapsed time (Condition: initial TCE concentration $=10 \mathrm{mg} / \mathrm{L}$; amount of $\mathrm{ZBRC}=10 \mathrm{~g} ; \mathrm{pH}=7.0 \pm 0.2$; ultraviolet $\mathrm{C}$ intensity $=8.4 \mathrm{~mW} / \mathrm{cm}^{2}$ ). The error bars indicate the standard deviation.

A plausible coupled "sorption \& photodegradation" mechanism is shown in Figure 4. TCE molecules sorbed onto the surface of the BR support located in the vicinity of ZnO particles were transported from the surface of the BR support to the $\mathrm{ZnO}$ particles, and degraded into their intermediates by photocatalytic activity. Finally, those intermediates that were more vulnerable to oxidation were sorbed, and easily degraded by photocatalytic activity. Because competitive sorption between BR supports and $\mathrm{ZnO}$ particles was expected, the TCE molecules were sorbed and diffused into the surface of the BR support when the photocatalytic degradation rate of $\mathrm{ZnO}$ particles was significantly low. However, the net result was a synergistic increase in the removal of TCE from the aqueous phase both by the sorption to BR supports and by the enhanced photocatalytic activity of the $\mathrm{ZnO}$ particles.

Table 2 presents the photocatalytic efficiency of ZBRC $\left(K_{\mathrm{app}}=0.067 \mathrm{~min}^{-1}\right)$, which was two times higher than that of the nanoscale $\mathrm{ZnO}$ particles $\left(K_{\mathrm{app}}=0.030 \mathrm{~min}^{-1}\right)$, although the surface area of the nanoscale $\mathrm{ZnO}$ particles exposed to UV irradiation was expected to be higher. Given that the photocatalytic reaction rate $\left(K_{\mathrm{app}}\right)$ is proportional to the fraction of the surface coverage by TCE to be degraded [2,10], this result could be due to the fact that the surface of the ZBRC was covered with the sorbed TCE molecules, resulting in a higher TCE removal efficiency through coupled reaction processes (sorption, photolysis, and photocatalysis). Additionally, the deposition of nanoscale $\mathrm{ZnO}$ particles could reduce the UV intensity flux and block the $\mathrm{ZnO}$ surface available for photon sorption. 


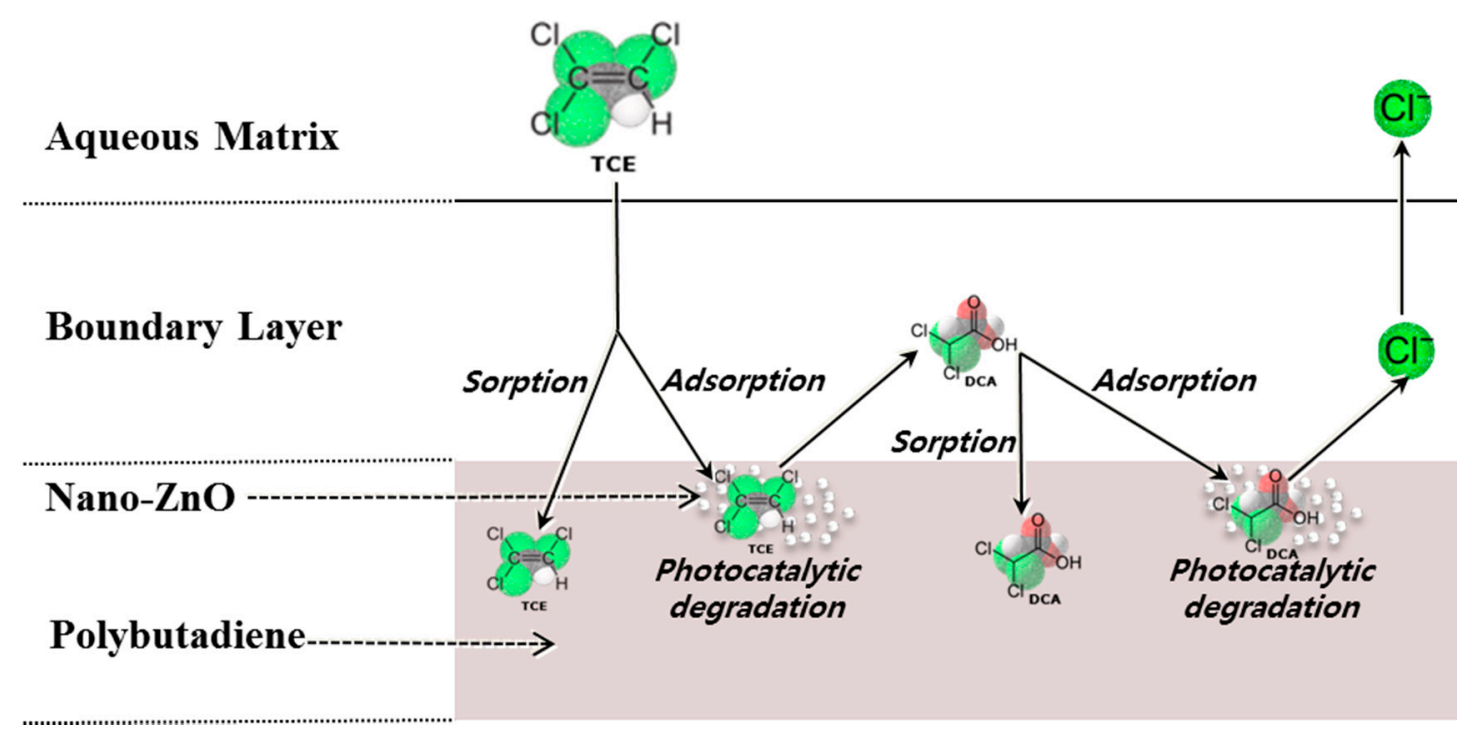

Figure 4. Plausible coupled removal mechanisms (sorption \& photodegradation) of TCE in the aqueous phase using ZBRC in a batch photocatalytic reactor.

Table 2. Summary of the apparent first-order degradation rate constants $\left(K_{\text {app }}\right)$ of trichloroethylene under various conditions.

\begin{tabular}{|c|c|c|c|c|c|c|}
\hline Test (Effect) & $\begin{array}{l}\text { Initial Conc. } \\
(\mathrm{mg} / \mathrm{L})\end{array}$ & $\begin{array}{l}\text { Loading } \\
\text { Amount } \\
(\mathrm{g} / 76 \mathrm{~mL})\end{array}$ & $\begin{array}{c}\text { Intensity of } \\
\text { Lamp } \\
\left(\mu \mathrm{W} / \mathrm{cm}^{2}\right)\end{array}$ & $\mathrm{pH}$ & $\begin{array}{c}K_{\text {app }} \\
\left(\min ^{-1}\right)\end{array}$ & $R^{2}$ \\
\hline UV only (photolysis) & 10 & N.A. ${ }^{a}$ & 84 & 7.0 & 0.012 & 0.993 \\
\hline $\mathrm{UV}$ + nano-ZnO particles & 10 & 0.05 & 84 & 7.0 & $0.030 \pm 0.006$ & 0.966 \\
\hline \multicolumn{7}{|c|}{ 1. Effect of Loading Amount } \\
\hline 1.1 & 10 & 1 & 84 & 7.0 & $0.016 \pm 0.004$ & 0.993 \\
\hline 1.2 & 10 & 5 & 84 & 7.0 & $0.037 \pm 0.004$ & 0.979 \\
\hline 1.3 & 10 & 10 & 84 & 7.0 & $0.066 \pm 0.002$ & 0.999 \\
\hline 1.4 & 10 & 15 & 84 & 7.0 & $0.096 \pm 0.001$ & 0.998 \\
\hline \multicolumn{7}{|c|}{ 2. Effect of Initial Concentration } \\
\hline 2.1 & 0.5 & 10 & 84 & 7.0 & $0.243 \pm 0.045$ & 0.999 \\
\hline 2.2 & 1 & 10 & 84 & 7.0 & $0.139 \pm 0.011$ & 0.996 \\
\hline 2.3 & 5 & 10 & 84 & 7.0 & $0.107 \pm 0.004$ & 0.996 \\
\hline 2.4 & 10 & 10 & 84 & 7.0 & $0.067 \pm 0.003$ & 0.997 \\
\hline 2.5 & 20 & 10 & 84 & 7.0 & $0.051 \pm 0.001$ & 0.999 \\
\hline \multicolumn{7}{|c|}{ 3. Effect of Lamp Intensity } \\
\hline 3.1 & 10 & 10 & 21 & 7.0 & $0.029 \pm 0.004$ & 0.982 \\
\hline 3.2 & 10 & 10 & 42 & 7.0 & $0.051 \pm 0.005$ & 0.999 \\
\hline 3.3 & 10 & 10 & 63 & 7.0 & $0.051 \pm 0.009$ & 0.997 \\
\hline 3.4 & 10 & 10 & 84 & 7.0 & $0.067 \pm 0.011$ & 0.997 \\
\hline \multicolumn{7}{|c|}{ 4. Effect of $\mathrm{pH}$} \\
\hline 4.1 & 10 & 10 & 84 & 4.0 & $0.055 \pm 0.001$ & 0.995 \\
\hline 4.2 & 10 & 10 & 84 & 7.0 & $0.056 \pm 0.002$ & 0.992 \\
\hline 4.3 & 10 & 10 & 84 & 10.0 & $0.067 \pm 0.001$ & 0.999 \\
\hline
\end{tabular}

Thus, an innovative ZBRC using both the nanoscale $\mathrm{ZnO}$ particles and the BR support with an excellent sorption capacity for chlorinated hydrocarbons was developed to overcome the various limitations in the application of nanoscale $\mathrm{TiO}_{2}$ and $\mathrm{ZnO}$ particles for various water resources. Compared to that of the nanoscale $\mathrm{TiO}_{2}$ and $\mathrm{ZnO}$ particles, the coupled TCE removal efficiency using ZBRC was greater because multiple reaction processes (i.e., sorption, photolysis, and photocatalysis) 
synergistically occurred at the same time. Quantitative characterization of reactive transitory species produced in ZBRC systems is warranted to elucidate the superior photocatalytic activity of ZBRC systems.

\subsection{Effect of the Initial TCE Concentration}

Figure 5 displays the effect of the initial TCE concentration on the degradation rate with $10 \mathrm{~g}$ of ZBRC. The degradation rate decreased with an increase in the initial TCE concentration. As summarized in Table 1, the $K_{\text {app }}$ values decreased from $0.243 \mathrm{~min}^{-1}$ to $0.051 \mathrm{~min}^{-1}$ as the initial TCE concentration increased from $0.5 \mathrm{mg} / \mathrm{L}$ to $20 \mathrm{mg} / \mathrm{L}$. Thus, a variation in the initial TCE concentration resulted in different irradiation times which were necessary to achieve complete degradation of the TCE.

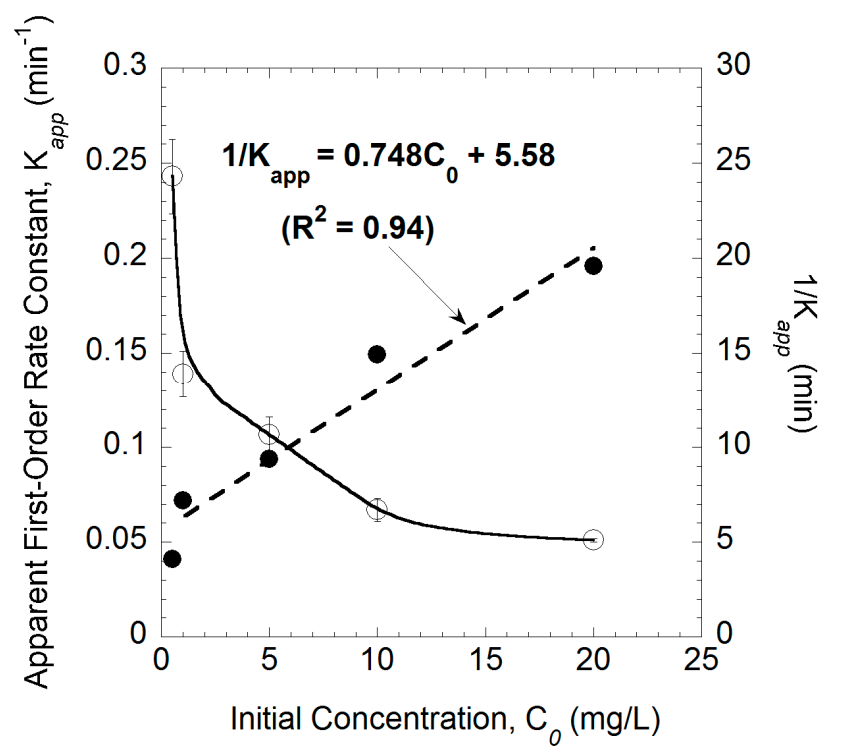

Figure 5. Effect of the initial TCE concentration on the degradation rate (Condition: amount of $\mathrm{ZBRC}=10 \mathrm{~g} ; \mathrm{pH}=7.0 \pm 0.2 ; \mathrm{UVC}$ intensity $\left.=8.4 \mathrm{~mW} / \mathrm{cm}^{2}\right)$. The error bars indicate the standard deviation, and the dashed line represents the linear relationship between $1 / K_{\text {app }}$ and the initial concentration of TCE $\left(C_{0}\right)$.

This phenomenon is due to the fact that the TCE molecules saturated the ZBRC surface and reduced the photonic efficiency, leading to photocatalyst deactivation $[4,7,10,21,22]$. Additionally, continuously-produced intermediates could be competitively sorbed and degraded by the photocatalytic activity; thus, the degradation of TCE was interfered at high concentrations of TCE. In the bulk solutions, more photons were sorbed by more TCE molecules at high concentrations of TCE. Consequently, the TCE removal rate decreased with an increase in the initial TCE concentration because of both the inhibited generation of electron-hole pairs and the shortage of photons to activate $\mathrm{ZnO}$.

As shown in Figure 5, a linear regression $\left(R^{2}=0.94\right)$ between $1 / K_{\text {app }}$ and the initial TCE concentration $\left(C_{0}\right)$ through the overall TCE concentration ranges tested was obtained from Equation (2), and both the sorption of TCE to ZBRC $\left(K_{\mathrm{S}}\right)$ and the photocatalytic degradation of TCE by ZnO $\left(K_{\mathrm{r}}\right)$ were estimated to be $0.134 \mathrm{~L} / \mathrm{mg}$ and $1.34 \mathrm{mg} / \mathrm{L} / \mathrm{min}$, respectively. The large value of $K_{\mathrm{r}}$ indicates that TCE removal mainly occurred by the photocatalytic degradation of the immobilized $\mathrm{ZnO}$ on the surface of ZBRC. Although the heterogeneous photocatalytic reactions of the immobilized $\mathrm{ZnO}$ were coupled with the excellent sorption capacity of BR, the sorption of TCE onto the photon activated $\mathrm{ZnO}$ was still rate-limited (see Figure 4). This result could be due to the fact that the sorbed TCE and the reaction intermediates on the surface of the ZBRC could also block the sorption of both $\mathrm{OH}^{-}$ ions and $\mathrm{O}_{2}$. As a result, the photocatalytic degradation of TCE on the surface of $\mathrm{ZnO}$ was critical 
in the removal of TCE, although the removal of TCE by ZBRC was a coupled and complex function consisting of sorption, photolysis, and photocatalysis.

\subsection{Effect of the ZBRC Loading Amounts}

The effects of the ZBRC loading amounts $(1,5,10$, and $15 \mathrm{~g})$ on the removal rates are shown in Figure 6. The $K_{\text {app }}$ value increased in the range of $0.016-0.096 \mathrm{~min}^{-1}$ as the loading amount of ZBRC $\left(M_{\text {ZBRC }}\right)$ increased (see Table 2$)$. Similar to previous findings in which the photocatalyst amounts were directly proportional to the overall photocatalytic reaction rates $[4,10,21,22]$, a linear regression $\left(R^{2}=0.99\right)$ between the $K_{\text {app }}$ value and the ZBRC loading amount $\left(M_{\mathrm{ZBRC}}\right)$ was obtained within the evaluated range of $M_{Z B R C}$.

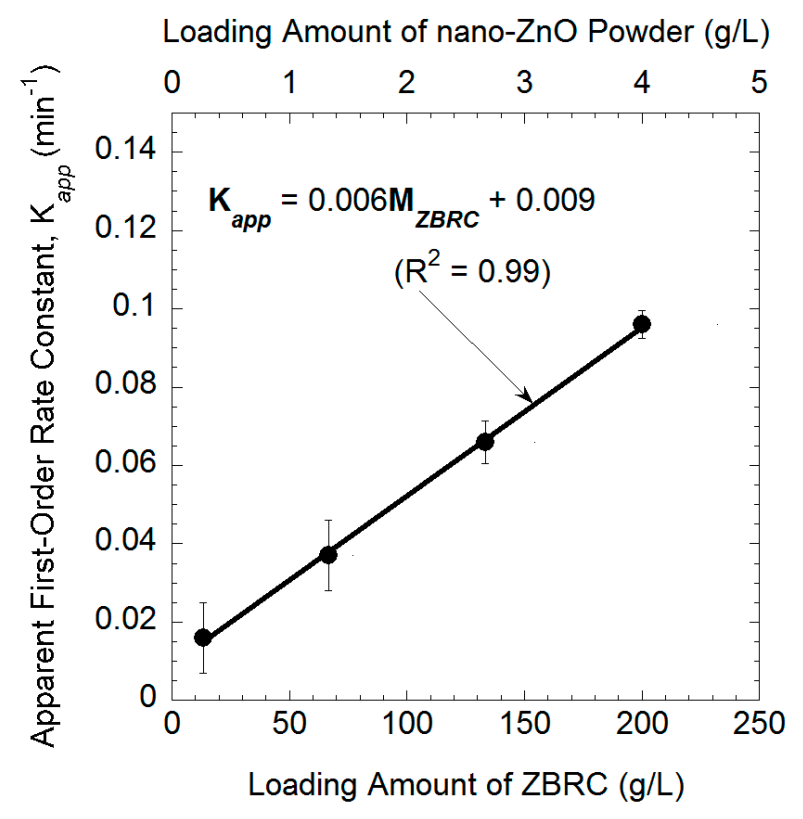

Figure 6. Effect of the loading amount of ZBRC on the TCE degradation rate (Condition: initial TCE concentration $=10 \mathrm{mg} / \mathrm{L} ; \mathrm{pH}=7.0 \pm 0.2 ; \mathrm{UVC}$ intensity $=8.4 \mathrm{~mW} / \mathrm{cm}^{2}$ ).

Because the increased $M_{\text {ZBRC }}$ increased the number of active sites available for both sorption and photocatalysis, more TCE and intermediate molecules were expected to be sorbed and degraded by the increased number of holes and $\cdot \mathrm{OH}$ radicals $[4,10]$. Although many previous studies have reported that the removal rate increased with an increase in the photocatalyst loading amounts up to some threshold value due to the screening effect of the UV light $[4,10,21,22]$, both threshold values and optimum catalyst loading were not observed within the range of $M_{\text {ZBRC }}$ evaluated in this study. These results could be attributed to the heterogeneous photocatalytic reactions of the immobilized nanoscale $\mathrm{ZnO}$ coupled with the excellent sorption capacity of the UV-transparent BR support.

The theoretical $K_{\text {app }}$ values for an initial TCE concentration of $10 \mathrm{mg} / \mathrm{L}$ and a loading of $10 \mathrm{~g}$ ZBRC can be estimated from the satisfactory linear correlations shown in Figures 5 and 6, which were 0.077 and $0.066 \mathrm{~min}^{-1}$, respectively, and were found to have a similarity of $86 \%$. Thus, based on the initial TCE concentration $\left(C_{0}\right)$ and the ZBRC loading amount $\left(M_{\mathrm{ZBRC}}\right)$, the theoretical $K_{\text {app }}$ values can be estimated, a priori, without performing photocatalytic experiments.

\subsection{Effect of Light Intensity}

When treating water resources, a relatively high light intensity is necessary to provide a sufficient amount of photon energy. Furthermore, the degradation rates of organic contaminants have been reported to increase with the radiation intensity $[4,7,10,23,24]$. Similarly, the $K_{\text {app }}$ values increased with the light intensity from $2.1 \mathrm{~mW} / \mathrm{cm}^{2}$ to $4.2 \mathrm{~mW} / \mathrm{cm}^{2}$, as shown in Figure 7. However, the dependency 
of the $K_{\text {app }}$ values on the light intensity was insignificant from $4.2 \mathrm{~mW} / \mathrm{cm}^{2}$ to $8.4 \mathrm{~mW} / \mathrm{cm}^{2}$. These results indicate that the initiation of the $\mathrm{ZnO}$ photocatalysis reaction is not significantly affected by the light intensity as long as a sufficient amount of photon energy (i.e., $4.2 \mathrm{~mW} / \mathrm{cm}^{2}$ ) is provided. Consistent with this study, Joo et al. [10] reported that photocatalytic efficiency was affected more by the loading amounts of the photocatalyst than by the light intensity.

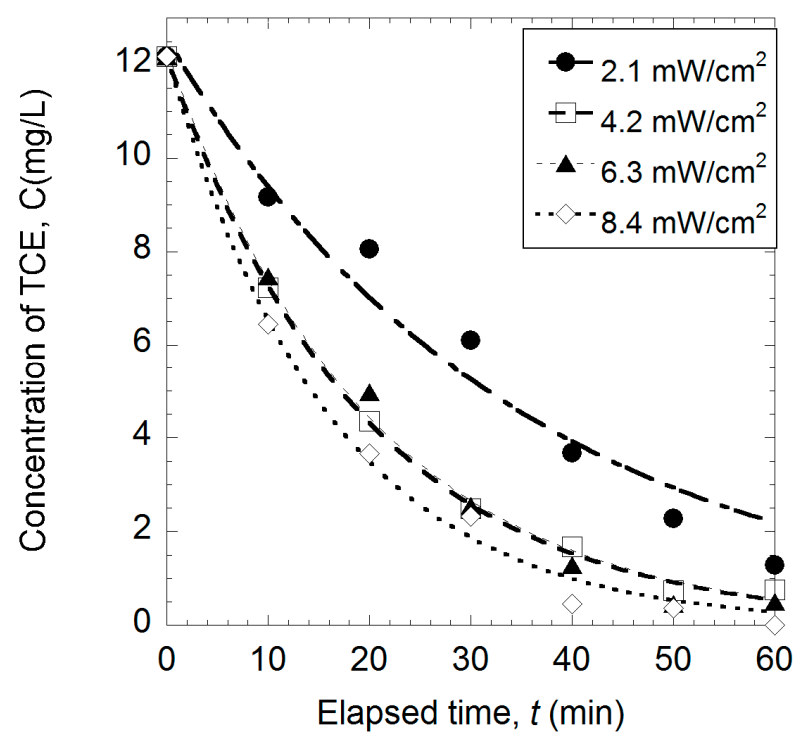

Figure 7. Effect of light intensity on the TCE degradation rate (Condition: initial TCE concentration = $10 \mathrm{mg} / \mathrm{L} ; \mathrm{ZBRC}$ amount $=10 \mathrm{~g} ; \mathrm{pH}=7.0 \pm 0.2$ ).

\subsection{Effect of $p H$}

The effect of the initial $\mathrm{pH}$ on the TCE degradation rate was evaluated with a fixed amount of ZBRC $(10 \mathrm{~g})$ and an initial TCE concentration of $10 \mathrm{mg} / \mathrm{L}$. As displayed in Figure 8, the values of $K_{\mathrm{app}}$ increased slightly as the $\mathrm{pH}$ increased, since the formation of $\cdot \mathrm{OH}$ at high $\mathrm{pH}$ values is expected. Similarly, at high $\mathrm{pH}$ values, an increased photocatalytic degradation of chlorinated hydrocarbons with synthesized $\mathrm{ZnO}$ photocatalysts was reported due to the enhanced formation of $\cdot \mathrm{OH}[5,10,25]$.

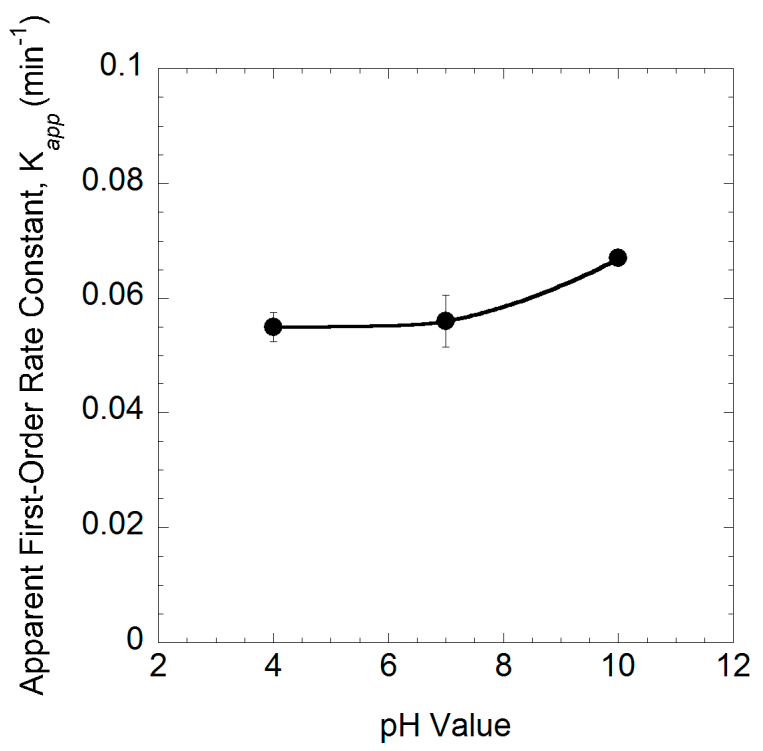

Figure 8. Effect of $\mathrm{pH}$ in aqueous solutions on the TCE degradation rate (Condition: initial TCE concentration $=10 \mathrm{mg} / \mathrm{L} ;$ ZBRC amount $=10 \mathrm{~g} ; \mathrm{UVC}$ intensity $=8.4 \mathrm{~mW} / \mathrm{cm}^{2}$ ). 
Although some, if any, of the nanoscale $\mathrm{ZnO}$ immobilized in the ZBRC might be dissociated at $\mathrm{pH}$ 4.0, the $K_{\mathrm{app}}$ values were still similar to those at $\mathrm{pH}$ 7.0. While the TCE removal efficiency by the immobilized $\mathrm{ZnO}$ decreased slightly at $\mathrm{pH} 4.0$, the sorption of TCE to BR increased due to the insufficient mobility of the TCE and intermediates around the surface of the ZBRC. Thus, the effect of the initial $\mathrm{pH}$ in aqueous solutions on the TCE degradation rate by $\mathrm{ZBRC}$ is insignificant.

\subsection{Response Surface Analysis}

Since the removal efficiencies of TCE using ZBRC systems were found to be dependent on operational parameters (i.e., the initial $\mathrm{pH}$, the loading amount of $\mathrm{ZBRC}$, and the intensity of light), response surface analysis was performed to identify the optimum experimental conditions. In this study, the central composite design method was used to analyze the interactions among the initial $\mathrm{pH}$, the loading amount of ZBRC, and the intensity of light on TCE removal. The coded and actual levels of parameters with experimental and predicted results are summarized in Table 3. As also displayed in Figure 9, the contour plots between two operational parameters indicated that the greater removal efficiencies of TCE were achieved with higher $\mathrm{pH}$ values, greater amounts of $\mathrm{ZBRC}$, and a greater intensity of light.

Table 3. Coded and actual levels of variables with experimental and predicted results.

\begin{tabular}{lcccccccc}
\hline & \multicolumn{2}{c}{$\mathbf{p H}$} & \multicolumn{2}{c}{ ZBRC (g) } & \multicolumn{2}{c}{ Light Intensity (min) } & Removal Efficiency, RE (\%) \\
\cline { 2 - 8 } Run & $\begin{array}{c}\text { Coded } \\
\text { Value }\end{array}$ & $\begin{array}{c}\text { Actual } \\
\text { Value }\end{array}$ & $\begin{array}{c}\text { Coded } \\
\text { Value }\end{array}$ & $\begin{array}{c}\text { Actual } \\
\text { Value }\end{array}$ & $\begin{array}{c}\text { Coded } \\
\text { Value }\end{array}$ & $\begin{array}{c}\text { Actual } \\
\text { Value }\end{array}$ & Experimental & Predicted \\
\hline R1 & $(1)$ & 10 & $(1)$ & 10 & $(1)$ & 63 & 87.9 & 95.0 \\
R2 & $(\alpha)$ & 12 & $(0)$ & 5 & $(-1)$ & 42 & 85.8 & 81.7 \\
R3 & $(1)$ & 10 & $(1)$ & 10 & $(1)$ & 21 & 60.1 & 63.9 \\
R4 & $(-1)$ & 4 & $(-1)$ & 1 & $(0)$ & 21 & 49.1 & 42.7 \\
R5 & $(0)$ & 7 & $(0)$ & 5 & $(0)$ & 42 & 80.5 & 78.0 \\
R6 & $(0)$ & 7 & $(0)$ & 5 & $(0)$ & 42 & 81.0 & 78.0 \\
R7 & $(0)$ & 7 & $(0)$ & 5 & $(\alpha)$ & 84 & 98.9 & 93.0 \\
R8 & $(0)$ & 7 & $(-\alpha)$ & 0 & $(0)$ & 42 & 56.8 & 70.3 \\
R9 & $(0)$ & 7 & $(0)$ & 5 & $(0)$ & 42 & 80.0 & 78.0 \\
R10 & $(0)$ & 7 & $(0)$ & 5 & $(0)$ & 42 & 80.1 & 78.0 \\
R11 & $(0)$ & 7 & $(0)$ & 5 & $(-\alpha)$ & 0 & 21.0 & 23.3 \\
R12 & $(1)$ & 10 & $(-1)$ & 1 & $(-1)$ & 21 & 58.0 & 53.7 \\
R13 & $(-1)$ & 4 & $(1)$ & 10 & $(-\alpha)$ & 63 & 86.4 & 91.8 \\
R14 & $(1)$ & 10 & $(-1)$ & 1 & $(-1)$ & 63 & 86.1 & 87.9 \\
R15 & $(-\alpha)$ & 2 & $(0)$ & 5 & $(0)$ & 42 & 67.7 & 69.4 \\
R16 & $(0)$ & 7 & $(\alpha)$ & 15 & $(1)$ & 42 & 92.2 & 84.5 \\
R17 & $(-1)$ & 4 & $(-1)$ & 1 & $(-1)$ & 63 & 83.3 & 80.8 \\
R18 & $(0)$ & 7 & $(0)$ & 5 & $(0)$ & 42 & 81.0 & 78.0 \\
R19 & $(0)$ & 7 & $(0)$ & 5 & $(0)$ & 42 & 80.1 & 78.0 \\
R20 & $(-1)$ & 4 & $(1)$ & 10 & $(\alpha)$ & 21 & 55.2 & 56.7 \\
\hline
\end{tabular}

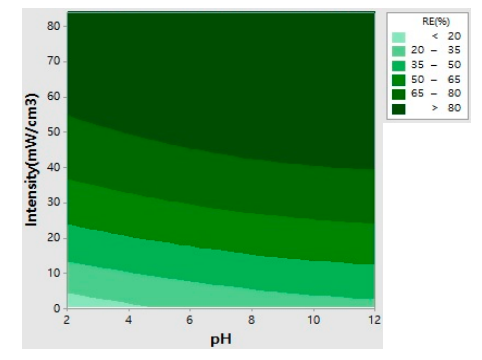

(a) Light intensity vs. $\mathrm{pH}$

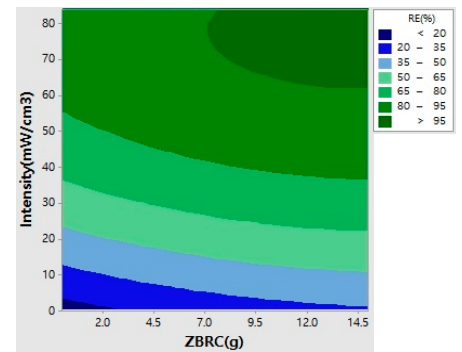

(b) Light intensity vs. ZBRC amount

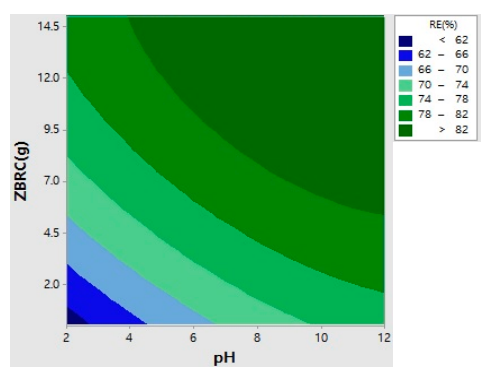

(c) ZBRC amount vs. $\mathrm{pH}$

Figure 9. Interaction effects among (a) the initial $\mathrm{pH},(\mathbf{b})$ the loading amount of $\mathrm{ZBRC}$, and (c) the intensity of light on TCE removal. 


\section{Materials and Methods}

\subsection{Nanoscale ZnO/Polybutadiene Rubber Composite (ZBRC)}

The nanoscale $\mathrm{ZnO}$ particles (99\% purity) used in this study were manufactured by Nabond Technologies (KL, Hong Kong, China) with an average diameter of $30 \mathrm{~nm}$ and a specific surface area of $90 \mathrm{~m}^{2} / \mathrm{g}$. Polybutadiene rubber (BR) (J.W.G. Co., Hong Kong, China), which is a synthetic rubber with branched structures, and excellent sorption capability, optical, and mechanical properties, was prepared as square specimens with a length of $3-5 \mathrm{~mm}$. Based on the chemical compatibility, $300 \mathrm{~g}$ of BR specimens were immersed in $3 \mathrm{~L}$ tetrahydrofuran (THF) (Daejung Chemical \& Metals Co., Siheung, Korea), which is an excellent polymer solvent with significant solubilizing capacity for many high molecular weight polymers with moderate viscosity [18]. Because the THF molecules were partitioned and diffused into the surface of the BR specimens, the surface of the BR specimens dissolved, and various pores, cracks, and channels of different sizes developed in the polymer matrix. Finally, further penetration of the THF molecules into the BR specimens increased the swollen and crosslinked surface layers.

After a two hour immersion, the THF molecule-penetrated swollen BR specimens were placed in a tray containing $100 \mathrm{~g}$ of nanoscale $\mathrm{ZnO}$ particles. The tray was then fixed to a shaker which was agitated at $100 \mathrm{rpm}$ for $5 \mathrm{~min}$ to physically entrap $\mathrm{ZnO}$ particles in the surface of the BR specimens with their various pores, cracks, and channels. Then, the $\mathrm{ZnO}$ particle-entrapped $\mathrm{BR}$ specimens were dried in an electric furnace at $130{ }^{\circ} \mathrm{C}$ for $5 \mathrm{~min}$. After the penetrated THF molecules rapidly evaporated, the swollen BR specimens contracted. As a result, $\mathrm{ZnO}$ particles were entrapped in the surface of the $\mathrm{BR}$ specimens by fixing nanoscale $\mathrm{ZnO}$ particles in the various sized pores, cracks, and channels. The fabricated nanoscale $\mathrm{ZnO} /$ polybutadiene rubber composite (ZBRC) with a specific surface area of 5-10 $\mathrm{m}^{2} / \mathrm{g}$ was rinsed with distilled water using an ultrasonic cleaner (POWERSONIC 420) (Hwashin Tech, Daegu, Korea) at $700 \mathrm{~W}$ for $30 \mathrm{~min}$ to remove any excess $\mathrm{ZnO}$ particles not trapped on the surface of the BR specimens. Finally, the ZBRC was dried at $100{ }^{\circ} \mathrm{C}$ for an hour to evaporate any moisture. A detailed manufacturing procedure of the ZBRC is summarized in the Figure S1.

\subsection{1,1,2-Trichloroethylene (TCE) and Analytical Methods}

Spectrophotometric grade $(\geq 99.5 \%)$ 1,1,2-trichloroethylene (TCE) was purchased from Sigma-Aldrich Chemical Co. (St. Louis, MO, USA). The detailed preparation procedure of the TCE solutions with different initial concentrations (i.e., $0.5,1,5,10$ and $20 \mathrm{mg} / \mathrm{L}$ ) is previously described elsewhere [10]. A sample from each batch photocatalytic reactor was collected according to the elapsed time (i.e., 0, 10, 20, 30, 40, 50, and $60 \mathrm{~min}$ ). The detailed extraction and measurement procedures of TCE from the aqueous phase is also previously described elsewhere [10]. The changes in total organic carbon (TOC) were also observed using TOC analyzers (Shimadzu Co., Tokyo, Japan), adopting the $680^{\circ} \mathrm{C}$ combustion catalytic oxidation method.

\subsection{Batch Photocatalytic Reactor and Experimental Design}

A batch photocatalytic reactor (BPR), which was used previously [10], was utilized throughout the whole study. All experiments were performed five times using TCE solutions with different initial concentrations (i.e., $0.5,1,5,10$, and $20 \mathrm{mg} / \mathrm{L}$ ) and different ZBRC loading amounts (i.e., 1, 5, 10, and $15 \mathrm{~g}$ ) for a reaction period of $60 \mathrm{~min}$, which was assumed to be similar to that of a preliminary study [10]. To compare the photocatalytic activities of the nanoscale $\mathrm{ZnO}$ between particle type (bare nanoscale $\mathrm{ZnO}$ ) and composite type (ZBRC), $0.05 \mathrm{~g}$ of nanoscale $\mathrm{ZnO}$ particles were dispersed in a $75 \mathrm{~mL}$ quartz reactor before the experiments, which was also based on a preliminary study $[9,10]$. 


\subsection{Kinetics of Photocatalytic Degradation}

In this study, the rate of coupled removal for TCE with ZBRC was described by the Langmuir-Hinshelwood (L-H) model [10]. At low concentrations (i.e., $K_{S} C<<1$ ), the Langmuir-Hinshelwood ( $\mathrm{L}-\mathrm{H})$ model simplifies to a pseudo-first-order kinetics as follows $[4,7,10]$ :

$$
-\frac{d C}{d t}=K_{r} K_{S} C=K_{a p p} C
$$

where $C$ is the concentration of TCE at time $t(\mathrm{mg} / \mathrm{L}) ; K_{\mathrm{r}}$ is the intrinsic reaction rate constant $(\mathrm{mg} / \mathrm{L} / \mathrm{min}) ; K_{\mathrm{S}}$ is the $\mathrm{L}-\mathrm{H}$ sorption constant $(\mathrm{L} / \mathrm{mg})$, and $K_{\mathrm{app}}$ is the apparent or lumped-first-order degradation rate constant $\left(\mathrm{min}^{-1}\right)$, because the sorption of TCE to ZBRC (i.e., $K_{S}$ ) occurs coupled with the photocatalytic degradation of TCE $\left(K_{\mathrm{r}}\right)$ under UV irradiation.

Additionally, the L-H model was successfully applied to estimate the relationship between the removal rate and the initial concentration of TCE during heterogeneous photocatalytic degradation, as follows $[4,7,10]$ :

$$
\frac{1}{K_{\text {app }}}=\frac{C_{0}}{K_{r}}+\frac{1}{K_{r} K_{S}}
$$

where $C_{0}$ is the initial concentration of TCE $(\mathrm{mg} / \mathrm{L})$. Based on this linear correlation, both the sorption of TCE to ZBRC $\left(K_{S}\right)$ and the photocatalytic degradation of TCE $\left(K_{\mathrm{r}}\right)$ can be estimated through the overall TCE concentration ranges tested.

\subsection{Response Surface Analysis}

Three independent variables for response surface analysis were the initial $\mathrm{pH}$, the loading amount of ZBRC, and the intensity of light on TCE removal, and the experimental design obtained by the full factorial central composite designs (CCD) were used. Statistical analysis was done using the software MINITAB (Version 14.12, State College, PA, USA, 2015), and the optimal values of the experimental conditions were obtained by analyzing the response surface contour plots.

\section{Summary and Conclusions}

A novel nanoscale $\mathrm{ZnO} /$ polybutadiene rubber composite (ZBRC) was fabricated as a valid alternative to $\mathrm{TiO}_{2}$ particles or immobilized $\mathrm{TiO}_{2}$ to mineralize chlorinated hydrocarbons without difficulties in filtration and recovery of the photocatalyst particles. The UV-transparent amorphous BR support in the ZBRC significantly sorbed TCE while a heterogeneous photocatalytic reaction occurred simultaneously between the TCE and the $\mathrm{ZnO}$ immobilized on the surface of the ZBRC. Thus, a synergistic increase was observed in the coupled removal of TCE from the aqueous phase by both sorption to the BR support and enhanced photocatalytic activity of the $\mathrm{ZnO}$ particles. The TCE removal rate decreased with an increase in the initial TCE concentration because of the inhibited generation of electron-hole pairs and the deficiency of photons to activate $\mathrm{ZnO}$. Moreover, the TCE removal rate increased with an increase in the ZBRC loading amount due to the increased number of active sites available for both sorption and photocatalysis. Based on the satisfactory linear regressions $\left(R^{2} \geq 0.94\right)$ between the apparent degradation rate constant $\left(K_{\mathrm{app}}\right)$ and the initial concentration vs. the ZBRC loading amount, the $K_{\text {app }}$ values can be estimated, a priori, without performing photocatalytic experiments. The photocatalytic efficiencies were affected more significantly by the changes in the initial TCE concentration and the ZBRC loading amounts rather than by changes in the light intensity and the $\mathrm{pH}$ in aqueous solutions. Based on the aforementioned results, an innovative ZBRC was developed using both nanoscale $\mathrm{ZnO}$ particles and a BR support with an excellent sorption capacity for chlorinated contaminants to overcome the drawbacks (filtration and recovery of catalysts, dispersion issues, etc.) in applications of nanoscale photocatalyst particles for various treatment processes of water resources. Further study is warranted to optimize the coupled reactions to maximize the removal efficiency in field scale reactors using multi-variable optimization approaches. 
Supplementary Materials: The following are available online at www.mdpi.com/2073-4344/6/10/152/s1. Figure S1: Preparation procedure of Nanoscale ZnO/Polybutadiene Rubber Composite (ZBRC). Figure S2: Scanning electron microscope (SEM) Images of polybutadiene rubber. Figure S3: Scanning electron microscope (SEM)/energy dispersive X-ray spectra of polybutadiene rubber. Figure S4: Scanning electron microscope (SEM) images of Nano-ZnO/polybutadiene Rubber Composites (ZBRC) at different magnifications. Figure S5: Scanning electron microscope (SEM)/energy dispersive X-ray spectra of Nano-ZnO/polybutadiene Rubber Composites (ZBRC). Figure S6: Scanning electron microscope (SEM) images of Nano-ZnO/polybutadiene Rubber Composites (ZBRC) at different magnifications after five runs. Figure S7: Scanning electron microscope (SEM) / energy dispersive X-ray spectra of Nano-ZnO/polybutadiene Rubber Composites (ZBRC) after five runs. Figure S8: X-ray diffraction (XRD) graphs of Laponite, polybutadiene Rubber (PBR), ZnO nanopowder, and Nano-ZnO/polybutadiene Rubber Composites (ZBRC) ball.

Acknowledgments: This study was partially supported by the Korea Ministry of Environment as "The GAIA project (No. 2012000550005)" and by the "Research Fund from Integrated Department (No. 201403040001)" of Hanbat National University in 2014.

Author Contributions: C.H.A. and J.S.C. conceived and designed the experiments; D.J.G. performed the experiments; J.H.K. and J.C.J. analyzed the data; J.K.K. contributed reagents/materials/analysis tools; D.J.G. and J.C.J. wrote the paper.

Conflicts of Interest: The authors declare no conflict of interest.

\section{References}

1. Crittenden, J.C.; Liu, J.; Hand, D.W.; Perram, D.L. Photocatalytic oxidation of chlorinated hydrocarbons in water. Water Res. 1997, 31, 429-438. [CrossRef]

2. Yamazaki, S.; Matsunaga, S.; Hori, K. Photocatalytic degradation of trichloroethylene in water using $\mathrm{TiO}_{2}$ pellets. Water Res. 2001, 35, 1022-1028. [CrossRef]

3. Daneshvar, N.; Ayazloo, M.; Khataee, A.R.; Pourhassan, M. Biological decolorization of dye solution containing Malachite Green by microalgae Cosmarium sp. Bioresource Technol. 2007, 98, 1-7. [CrossRef] [PubMed]

4. Yang, L.; Yu, L.E.; Ray, M.B. Degradation of paracetamol in aqueous solutions by $\mathrm{TiO}_{2}$ photocatalysis. Water Res. 2008, 42, 3480-3488. [CrossRef] [PubMed]

5. Gaya, U.I.; Abdullah, A.H.; Zainal, Z.; Hussein, M.Z. Photocatalytic treatment of 4-chlorophenol in aqueous ZnO suspensions: Intermediates, influence of dosage and inorganic anions. J. Hazard. Mater. 2009, 168, 57-63. [CrossRef] [PubMed]

6. Yokosuka, Y.; Oki, K.; Nishikiori, H.; Tatsumi, Y.; Tanaka, N.; Fujii, T. Photocatalytic degradation of trichloroethylene using $\mathrm{N}$-doped $\mathrm{TiO}_{2}$ prepared by a simple sol-gel process. Res. Chem. Intermed. 2009, 35, 43-53. [CrossRef]

7. Chong, M.N.; Jin, B.; Chow, C.W.K.; Saint, C. Recent developments in photocatalytic water treatment technology: A review. Water Res. 2010, 44, 2997-3027. [CrossRef] [PubMed]

8. Di Paola, A.; García-López, E.; Marcì, G.; Palmisano, L. A survey of photocatalytic materials for environmental remediation. J. Hazard. Mater. 2012, 211-212, 3-29. [CrossRef] [PubMed]

9. Doria, F.C.; Borges, A.C.; Kim, J.K.; Nathan, A.; Joo, J.C.; Campos, L.C. Removal of metaldehyde through photocatalytic reactions using nano-sized zinc oxide composites. Water Air Soil Pollut. 2013, 224, 1434-1442. [CrossRef]

10. Joo, J.C.; Ahn, C.H.; Jang, D.G.; Yoon, H.H.; Kim, J.K.; Campos, L.; Ahn, H.S. Photocatalytic degradation of trichloroethylene in aqueous phase using nano-ZNO/Laponite composites. J. Hazard. Mater. 2013, 263, 569-574. [CrossRef] [PubMed]

11. Hariharan, C. Photocatalytic degradation of organic contaminants in water by $\mathrm{ZnO}$ nanoparticles: Revisited. Appl. Catal. A 2006, 304, 55-61. [CrossRef]

12. Mozia, S. Photocatalytic membrane reactors (PMRs) in water and wastewater treatment: A review. Sep. Purif. Technol. 2010, 73, 71-91. [CrossRef]

13. Leong, S.; Razmjou, A.; Wang, K.; Hapgood, K.; Zhang, X.; Wang, H. TiO 2 based photocatalytic membranes: A review. J. Membraine Sci. 2014, 472, 167-194. [CrossRef]

14. Zhu, J.; Zheng, W.; He, B.; Zhang, J.; Anpo, M. Characterization of Fe-TiO 2 photocatalysts synthesized by hydrothermal method and their photocatalytic reactivity for photodegradation of XRG dye diluted in water. J. Mol. Catal. A 2004, 216, 35-43. [CrossRef] 
15. Shan, A.Y.; Ghazi, T.I.M.; Rashid, S.A. Immobilisation of titanium dioxide onto supporting materials in heterogeneous photocatalysis: A review. Appl. Catal. A 2010, 389, 1-8. [CrossRef]

16. Xiang, Q.; Yu, J.; Wong, P.K. Quantitative characterization of hydroxyl radicals produced by various photocatalysts. J. Colloid Interface Sci. 2011, 357, 163-167. [CrossRef] [PubMed]

17. Dindar, B.; Içli, S. Unusual photoreactivity of zinc oxide irradiated by concentrated sunlight. J. Photochem. Photobiol. A 2001, 140, 263-268. [CrossRef]

18. Tian, M.; Hu, Q.; Wu, H.; Zhang, L.; Fong, H.; Zhang, L. Formation and morphological stability of polybutadiene rubber fibers prepared through combination of electrospinning and in-situ photo-crosslinking. Mater. Lett. 2011, 65, 3076-3079. [CrossRef]

19. Joo, J.C.; Kim, J.Y.; Nam, K. Mass transfer of organic compounds in dilute aqueous solutions into high density polyethylene geomembranes. J. Environ. Eng. 2004, 130, 175-183. [CrossRef]

20. Joo, J.C.; Nam, K.; Kim, J.Y. Estimation of mass transport parameters of organic compounds through high density polyethylene geomembranes using a modifield double-compartment apparatus. J. Environ. Eng. 2005, 131, 790-799. [CrossRef]

21. Behnajady, M.A.; Modirshahla, N.; Daneshvar, N.; Rabbani, M. Photocatalytic degradation of an azo dye in a tubular continuous-flow photoreactor with immobilized $\mathrm{TiO}_{2}$ on glass plates. Chem. Eng. J. 2006, 127, 167-176. [CrossRef]

22. Yang, H.; Ana, T.; Li, G.; Song, W.; Cooper, W.J.; Luo, H.; Guo, X. Photocatalytic degradation kinetics and mechanism of environmental pharmaceuticals in aqueous suspension of $\mathrm{TiO}_{2}$ : A case of blockers. J. Hazard. Mater. 2010, 179, 834-839. [CrossRef] [PubMed]

23. Sakthivel, S.; Neppolian, B.; Shankar, M.V.; Arabindoo, B.; Palanichamy, M.; Murugesan, V. Solar photocatalytic degradation of azo dye: Comparison of photocatalytic efficiency of $\mathrm{ZnO}$ and $\mathrm{TiO}_{2}$. Sol. Energy Mater. Sol. Cells 2003, 77, 65-82. [CrossRef]

24. Munesh, S.; Meena, R.C. Photocatalytic degradation of textile dye through an alternative photocatalyst methylene blue immobilized resin dowex 11 in presence of solar light. Arch. Appl. Sci. Res. 2012, 4, 472-479.

25. El-Kemary, M.; El-Shamy, H.; El-Mehasseb, I. Photocatalytic degradation of ciprofloxacin drug in water using ZnO nanoparticles. J. Lumin. 2010, 130, 2327-2331. [CrossRef]

(C) 2016 by the authors; licensee MDPI, Basel, Switzerland. This article is an open access article distributed under the terms and conditions of the Creative Commons Attribution (CC-BY) license (http://creativecommons.org/licenses/by/4.0/). 